\title{
Self-labeled magneto nanoprobes using tri-aminated polysorbate 80 for detection of human mesenchymal stem cells $\dagger$
}

\author{
Eun-Kyung Lim, ${ }^{a}$ Jaemoon Yang, ${ }^{b}$ Jin-Suck Suh, ${ }^{b}$ Yong-Min Huh ${ }^{* b}$ and Seungjoo Haam ${ }^{* a}$ \\ Received 22nd June 2009, Accepted 23rd September 2009 \\ First published as an Advance Article on the web 22nd October 2009 \\ DOI: $10.1039 / b 912149 h$
}

Self-labeled magneto nanoprobes (SLMNs) were synthesized for one-step labeling of human mesenchymal stem cells (hMSCs) via non-invasive magnetic resonance (MR) image tracking. The surface of superparamagnetic nanocrystals (SMNCs) were enveloped by tri-aminated polysorbate 80 (TP80) not only for enhancement of the affinity for hMSCs, but also to achieve increased colloidal stability in the aqueous phase by the nanoemulsion method. The synthesized SLMNs exhibited excellent labeling efficiency of hMSCs and produced highly sensitive MR signals as well as safe cell cytotoxicity.

\section{Introduction}

Stem cell therapy has come of age for the treatment of various diseases through cell transplantation at defunct cell populations. ${ }^{1-7}$ The trafficking and monitoring of cell migration during stem cell therapy is an important issue for understanding the temporal and spatial fate and distribution of transplanted stem cells. ${ }^{1,3,4,6,8-13}$

Because non-invaasive magnetic resonance (MR) imaging can rapidly acquire multi-informational high resolution images, magnetic labeling of stem cells with super-paramagnetic iron oxide particles can provide critical information about the cellular migration of the stem cells. ${ }^{2,6,7,14,15}$

For intracellular labeling agents, the FDA-approved ferumoxides have been conventionally available and can be complexed with polycationic transfection agents (e.g. poly-L-lysine (PLL), protamine sulfate (PS)). The positively charged surface properties of ferumoxides enable highly efficient cellular uptake through electrostatic interactions with the negatively charged cellular membranes. ${ }^{16-21}$

However, we have noticed that the use of ferumoxide-PLL complexes results in oxidative stress and injury of the cells due to formation of reactive oxygen species (ROS) and hydroxyl-free radicals, which, may also alter cell metabolism or increase the rate of apoptosis or cell death. ${ }^{10,22,23}$ The intracellular labeling efficiency and long period tracking capability is dependent on the concentration of tracking agents, even after cell differentiation. However, the use of large amounts of labeling agents results in increased cellular toxicity. ${ }^{1,8,13}$

The necessary and sufficient conditions for appropriate cellular labeling with MR contrast agents are (i) a high intracellular labeling efficiency, (ii) ultrasensitivity of magnetic

${ }^{a}$ Department of Chemical and Biomolecular Engineering, Yonsei University, Seoul 120-749, South Korea.E-mail: haam@yonsei.ac.kr; Fax: +82-2-312-6401; Tel: +82-2-2123-3554

${ }^{b}$ Department of Radiology, College of Medicine, Yonsei University, Seoul 120-752, South Korea

$\dagger$ Electronic supplementary information (ESI) available: Supporting spectra. See DOI: 10.1039/b912149h properties and (iii) maintenance of cellular-proliferation and differentiation capacity (biocompatibility).

Herein, we synthesized self-labeled magneto nanoprobes (SLMNs) by the nanoemulsion method using polycationic triaminated polysorbate 80 (TP80) which stabilizes and envelopes magnetic nanocrystals (MNCs) (Fig. 1). For enhancing the cationic property and stabilizing the capability in the aqueous phase, tri-aminated polysorbate 80 (TP80) was synthesized so that the terminal groups of polysorbate 80 would substitute the hydroxy groups with amine groups. We evaluated the physico-chemical properties of nanoparticles to confirm their nano-structures and characteristic features. Furthermore, we carefully investigated the cellular labeling and imaging efficiency of SLMNs using MR imaging and an in vitro MTT assay.

\section{Experimental}

\subsection{Materials}

Polysorbate 80 (polyoxyethylene sorbitan monooleate), ethylenediamine (EDA), 1,1'-carbonyldiimidazole (CDI), 1,4-dioxane

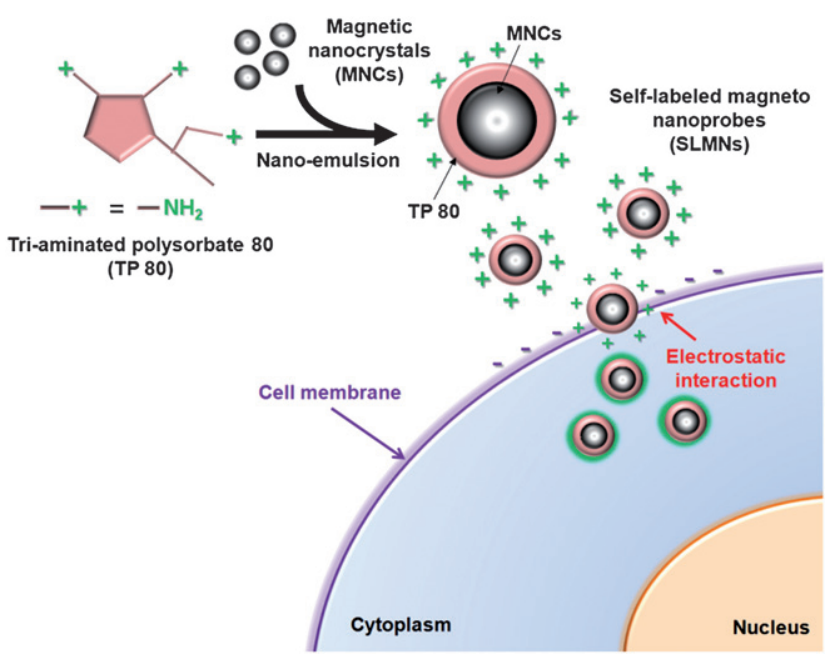

Fig. 1 Schematic of preparation of self-labeled magneto nanoprobes (SLMNs) for MR imaging. 
(99.8\%), and poly-L-lysine were purchased from Sigma Aldrich Chemical Co. Ferumoxides (Feridex I.V. ${ }^{\circledR}$ ) as commercial magnetic resonance (MR) imaging contrast agents were provided by the manufacturer (11.2 mg Fe/mL, Bayer HealthCare Pharmaceuticals Inc., Wayne, NJ, USA). Phosphate buffered saline (PBS; $10 \mathrm{mM}, \mathrm{pH}$ 7.4), DMEM and fetal bovine serum were purchased from Gibco. Vybrant ${ }^{\circledR}$ Apoptosis Assay Kit \#3 was purchased from Molecular probes (Eugene, USA). 2,4,6-Trinitrobenzene sulfonic acid (TNBSA) was purchased from Pierce (Thermo scientific, USA) and dialysis membrane (MWCO: 1000) was obtained from Spectrum laboratory. Human mesenchymal stem cells (hMSCs) were purchased from Young@science. All other chemicals and reagents were of analytical grade.

\subsection{Synthesis of $\mathrm{MnFe}_{2} \mathrm{O}_{4}$ nanocrystals (MNCs)}

We synthesized monodispersed $\mathrm{MnFe}_{2} \mathrm{O}_{4}$ nanocrystals (MNCs), which are soluble in non-polar organic solvents. ${ }^{24,25}$ Briefly, $2 \mathrm{mmol}$ of iron(III) acetylacetonate, $1 \mathrm{mmol}$ of manganese(II) acetylacetonate, $10 \mathrm{mmol}$ of 1,2-hexadecanediol, $6 \mathrm{mmol}$ of dodecanoic acid, and $6 \mathrm{mmol}$ of dodecylamine were dissolved in $20 \mathrm{~mL}$ of benzyl ether under an ambient nitrogen atmosphere. The mixture was then pre-heated to $200{ }^{\circ} \mathrm{C}$ for $2 \mathrm{~h}$ and refluxed at $300{ }^{\circ} \mathrm{C}$ for $30 \mathrm{~min}$. After the reactants were cooled at room temperature, the products were purified with an excess of pure ethanol. Approximately $12 \mathrm{~nm}$ of MNCs were synthesized using the seed-mediated growth method.

\subsection{Synthesis of tri-aminated polysorbate 80 (TP80)}

To modify the surface of MNCs with amine groups, we first synthesized tri-aminated polysorbate 80 (TP80) using CDI as

(a)
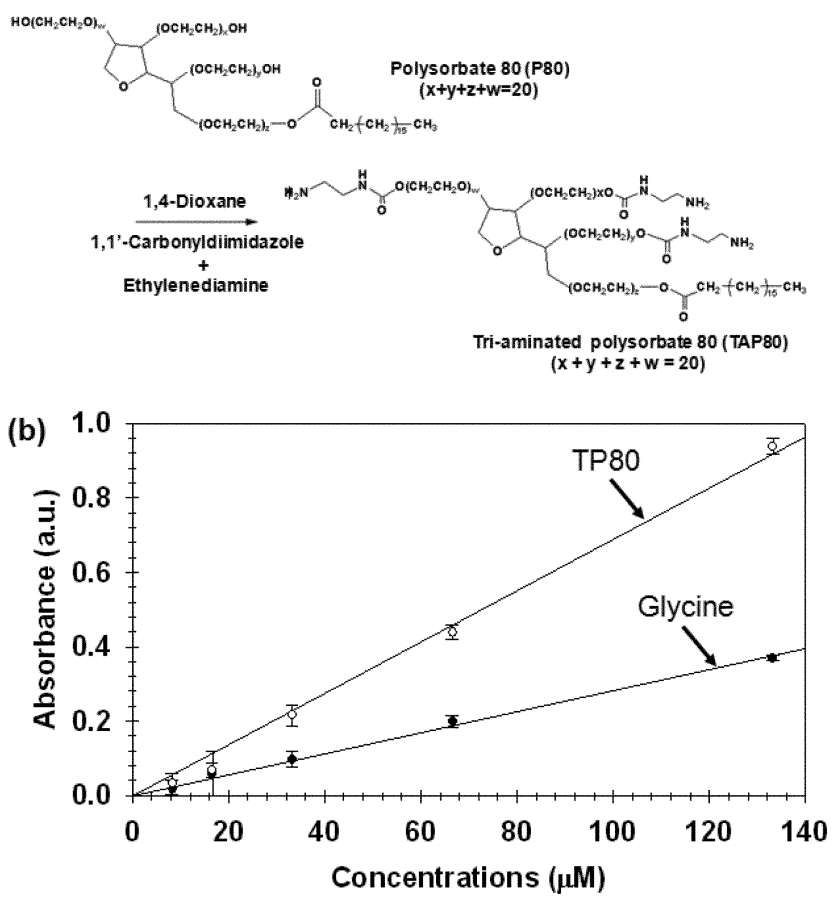

Fig. 2 (a) Synthetic diagram of tri-aminated polysorbate 80 (TP80) and (b) the determination of amine groups in tri-aminated polysorbate 80 (TP80) and glycine using TNBS assay. a zero-length crosslinker (Fig. 2 (a)). ${ }^{26,27} 5 \mathrm{mmol}$ of P80 and $15 \mathrm{mmol}$ of CDI were dissolved in a flask containing $100 \mathrm{~mL}$ of 1,4-dioxane and the reactant solution was stirred for $1 \mathrm{~h}$. Subsequently, $15 \mathrm{mmol}$ of EDA was added into the reactor at room temperature. After further reaction for $24 \mathrm{~h}$, the un-wanted solvent was rapidly eliminated using a rotary evaporator. The obtained transparent gel type product was then dissolved in $10 \mathrm{~mL}$ of deionized water and dialyzed against excess aqueous phase for over seven days. The purified product was freeze-dried and stored under vacuum for later use. The chemical structure of TP80 was characterized by ${ }^{1} \mathrm{H}-\mathrm{NMR}(400 \mathrm{MHz}$, Varian INOVA400 NMR spectrometer) using $\mathrm{CDCl}_{3}$ as a solvent. The characteristic bands of synthesized TP80 and P80 were confirmed by Fourier-transform infrared spectroscopy (FT-IR, Varian, Excalibur $^{\mathrm{TM}}$ series).

\subsection{Determination of amine groups in TP80}

To measure the primary amine groups in TP80, which were dissolved in $0.1 \mathrm{M}$ sodium bicarbonate buffer $(\mathrm{pH} 8.5)$ at various concentrations $(8.33-133.21 \mu \mathrm{M}), 0.5 \mathrm{~mL}$ of TP80 solution was mixed with a $0.01 \%(w / v)$ TNBSA solution. Subsequently, the mixed solution was stored at $37{ }^{\circ} \mathrm{C}$ for $2 \mathrm{~h}$. Then we added $0.25 \mathrm{ml}$ of $1 \%$ sodium dodecyl sulfate (SDS) and $0.125 \mathrm{ml}$ of $1 \mathrm{M}$ hydrochloride $(\mathrm{HCl})$ to the TP80 solution. As a control, glycine was prepared in the same manner. The absorbance of TP80 and glycine solution was analyzed using a UV-Vis spectrometer at 355 nm (Optizen 2120UV, MECASYS Co.).

\subsection{Preparation of self-labeled magneto nanoprobes (SLMNs)}

SLMNs were prepared by nanoemulsion method. ${ }^{28} 50 \mathrm{mg}$ of MNCs were dissolved in $4 \mathrm{~mL}$ of hexane (as the organic phase) and the organic phase was mixed with $20 \mathrm{~mL}$ of phosphate buffer saline (as the aqueous phase) containing $100 \mathrm{mg}$ of TP80. After mutual saturation of organic and aqueous phases, the emulsion was ultra-sonicated in an ice-cooled bath for $10 \mathrm{~min}$ at $450 \mathrm{~W}$. The organic solvent was evaporated overnight at room temperature and the products were purified by centrifugal filter (Centriprep YM-3, 3 kDa NMWL, Amicon and USA) with two cycles at $3000 \mathrm{~g}$ force for $1 \mathrm{~h}$. The amount of amine groups in the SLMNs were measured by a TNBSA assay. The size distribution and zeta-potential of SLMNs were analyzed using laser scattering (ELS-Z, Otsuka electronics). The surface electrical charge of the prepared SLMNs was analyzed by gel electrophoresis in $1 \%$ agarose in buffer solution over a wide range of $\mathrm{pH}$ conditions $(\mathrm{pH} 3-11)$ at room temperature. The morphologies of SLMNs were confirmed using high resolution transmission electron microscope (HR-TEM, JEM-2100F, JEOL Ltd.). The magnetic properties of MNCs and SLMNs were evaluated using a vibrating-sample magnetometer (VSM; MODEL-7300, Lakeshore) at $298 \mathrm{~K}$ and the residual weight ratio (\%) of the MNCs in the SLMNs was analyzed with a thermo-gravimetric analyzer (SDT-Q600, TA instrument).

\subsection{Cell viability test of SLMNs against hMSCs}

The cytotoxic effect of SLMNs against hMSCs was evaluated by measuring the inhibition of cell growth using MTT assay. Briefly, hMSCs were seeded at a density of $1 \times 10^{4}$ cells/well in a 96-well 
plate and incubated overnight at $37{ }^{\circ} \mathrm{C}$. hMSCs were then incubated with SLMNs at various concentrations for $24 \mathrm{~h}$. The yellow tetrazolium salt of the MTT solution is reduced to purple formazan crystals in metabolically alive cells. The cell viabilities were obtained by calculating the ratio of the intensity of purple formazan in viable cells treated with SLMNs to the intensity in untreated control cells. Human mesenchymal stem cells (hMSCs) were seeded at a density of $1 \times 10^{6}$ cells/well in a culture flask for a week at $37^{\circ} \mathrm{C}$ and incubated with $80 \mu \mathrm{g}$ $\mathrm{mL}^{-1}$ of SLMNs with a medium containing serum for a further $24 \mathrm{~h}$. Then hMSCs incubated with SLMNs were collected by centrifugation and washed twice with phosphate buffer saline (6.7 mM, pH 7.4).

Further to confirm whether labeled SLMNs caused cellular damage of hMSCs, i.e., apoptosis and necrosis, we performed an annexin V-FITC/propidium iodide (PI) double staining test. ${ }^{29,30}$ After resuspending hMSCs in $100 \mu \mathrm{L}$ of $1 \mathrm{X}$ annexin-binding buffer, $5 \mu \mathrm{L}$ of annexin V-FITC solution and $1 \mu \mathrm{L}$ of PI solutions were injected and incubated with hMSCs for $15 \mathrm{~min}$ at room temperature in a dark room. The fluorescence-stained hMSCs were analyzed by FACScalibur (Beckton-Dickinson, Mansfield, MA) by monitoring the fluorescence activated cell after addition of an additional $400 \mu \mathrm{L}$ of $1 \mathrm{X}$ annexin-binding buffer.

\subsection{Cellular labeling efficiency of SLMNs}

Human mesenchymal stem cells $\left(1 \times 10^{6}\right.$ cells/well $)$ were incubated for a week in a culture dish and were then further incubated with SLMNs $\left(80 \mu \mathrm{g} \mathrm{mL}^{-1}\right)$ containing a medium with serum in $5 \% \mathrm{CO}_{2}$ for $24 \mathrm{~h}$ at $37^{\circ} \mathrm{C}$. Subsequently, hMSCs treated with SLMNs were washed twice with phosphate buffered solution ( $\mathrm{pH} 7.4$ and $10 \mathrm{mM})$, trypsinized $(0.5 \mathrm{mM})$, and harvested. The collected hMSCs were washed in triplicate using $0.2 \%$ fetal bovine serum and $0.02 \% \mathrm{NaN}_{3}$ in phosphate buffered solution ( $\mathrm{pH} 7.4$ and $10 \mathrm{mM}$ ). The MR imaging capability of SLMNs was estimated by MR imaging, Prussian blue staining (BX51 upright microscope, Olympus) and transmission electron microscopy (TEM, JEOL-1100). Furthermore, the concentration of hMNCs $(\mathrm{Fe}+\mathrm{Mn})$ of labeled SLMNs into hMSCs was determined by inductively coupled plasma automic emission spectroscopy (ICP-AES, Elan 6100, Perkin Elmer).

\subsection{In vitro MR imaging procedure}

All MR imaging experiments were performed with a $1.5 \mathrm{~T}$ clinical MRI instrument with a micro-47 surface coil (Intera; Philips Medical Systems, Best, the Netherlands). The T2 weights of the SLMNs solution and ferumoxides and hMSC treated with SLMNs were measured by the Carr-Purcell-Meiboom-Gill (CPMG) sequence at room temperature: $\mathrm{TR}=10 \mathrm{~s}, 32$ echoes with 12 milliseconds even echo space, number of acquisition $=1$, point resolution of $156 \times 156 \mu \mathrm{m}$, section thickness of $0.6 \mathrm{~mm}$. For T2-weighted MR imaging of the samples, the following parameters were adopted: resolution of $234 \times 234 \mu \mathrm{m}$, section thickness of $2.0 \mathrm{~mm}, \mathrm{TE}=60$ milliseconds, $\mathrm{TR}=4000$ milliseconds and the number of acquisitions $=1$. The relaxivity coefficient $\left(\mu \mathrm{M}^{-1} \mathrm{~s}^{-1}\right)$ is equal to the ratio of $\mathrm{R} 2\left(1 / \mathrm{T} 2, \mathrm{~s}^{-1}\right)$ to SLMNs and ferumoxides concentration.

\subsection{Statistical analysis}

All experiments were performed in triplicate and the values are expressed as the average \pm standard deviation. The statistical evaluation of the data was performed by analysis of variance (ANOVA), followed by Turkey's test for comparison of cell viability, and relative T2 signal in MR image from different groups. A $p<0.01$ was considered to be statistically significant.

\section{Results and discussion}

For the synthesis of SLMNs, the tri-hydroxyl group of polysorbate 80 (P80) was first modified with amine groups using ethylenediamine (EDA) and 1,1'-carbonyldiimidazole (CDI) as a zero-length cross linker. The synthetic scheme of tri-amine terminated polysorbate 80 (TP80) is depicted in Fig. 2 (a). First, the tri-hydroxyl groups of P80 were activated with CDI, and the conjugated imidazole group of activated P80 was attacked by the amine group of EDA. Finally, a stable carbamate bond was formed by coupling the hydroxyl group from P80 and an amine group from EDA. ${ }^{26,27}$ After the conjugation process, the chemical structure of TP80 was characterized using ${ }^{1} \mathrm{H}-\mathrm{NMR} ; \delta$ values of $2.0\left(-\mathrm{NH}_{2}\right), 2.91,3.22\left(-\mathrm{CH}_{2}-\right)$ and $7.11\left(-\mathrm{NH}{ }_{-}\right)$(ESI $\left.\dagger\right)$. Furthermore, the characteristic bands of TP80 were verified by FT-IR spectra; $3550 \mathrm{~cm}^{-1}$ (N-H stretching of amine group), $3400 \mathrm{~cm}^{-1}$ (C-N stretching of an amide group), $2400 \mathrm{~cm}^{-1}$ $\left(\mathrm{O}-\mathrm{CO}-\mathrm{CH}_{3}\right.$ stretching) and $1600 \mathrm{~cm}^{-1}(\mathrm{~N}-\mathrm{H}$ bending of and amine group) $(\mathrm{ESI} \dagger)$. Otherwise, the hydroxyl stretching at $3500 \mathrm{~cm}^{-1}$ from TP80 was no longer observed after modification of P80 terminal groups. The increment of molecular weights for TP80 was further confirmed using gel permeation chromatography (GPC). The retention time of tri-amine terminated polysorbate 80 was decreased compared to non-modified P80 due to conjugated EDA (ESI $\dagger$ ). The absorbance of the reactants was detected in proportion to the amount of amine groups $\left(-\mathrm{NH}_{2}\right)$ because TNBS (2,4,6-trinitrobenzene sulfonic acid) was reacted with an amine group and produced a chromogenic derivative. As shown in Fig. 2 (b), the absorbance of TP80 was three times higher in comparison with the one of glycine through the TNBS assay. These results confirmed that the tri-hydroxyl group of P80 were successfully modified with tri-amine groups.

To utilize the MR capability of SLMNs, the hydrophobic magnetic nanocrystals (MNCs) were encapsulated with amphiphilic TP80. The size and the zeta-potential value of SLMNs measured by laser scattering were $40.73 \pm 4.63 \mathrm{~nm}$ and $25.36 \pm$ $1.87 \mathrm{mV}$, respectively. The size of the SLMNs was larger than the hydrophobic magnetic nanocrystals because the hydrophilic parts $\left(-\mathrm{OCH}_{2} \mathrm{CH}_{2}-\right)$ of tri-aminated polysorbate 80 (TP80) on the surface of SLMNs were conjugated with water molecules via hydrogen bonding. Furthermore, the TEM image presented well dispersed SLMNs in the aqueous phase without any precipitation and aggregation $(\mathrm{ESI} \dagger)$.

The size of SLMNs was smaller compared to ferumoxides (commercial MR imaging agents, $62.30 \pm 2.94 \mathrm{~nm})(* p<0.01)$. Because of the large amounts $\left(2.78 \times 10^{20} \mathrm{ea} / \mathrm{mL}\right)$ of amine groups $\left(-\mathrm{NH}_{2}\right)$ on the surface of SLMNs, the zeta-potential value exhibited a strong positive charge compared with ferumoxide $(-24.79 \pm 0.37 \mathrm{mV})$ (Fig. 3 (a)). 

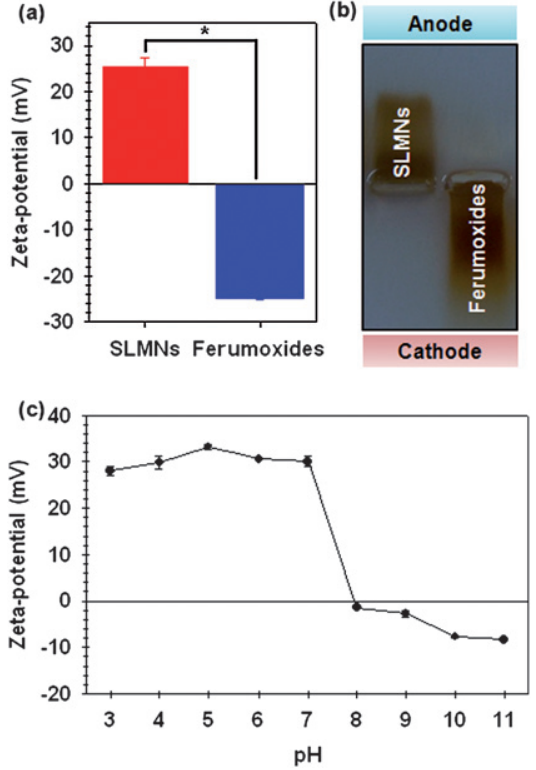

Fig. 3 (a) Size distribution and zeta-potential, (b) gel electrophoresis analysis of self-labeled magneto nanoprobes (SLMNs) and ferumoxides and (c) zeta-potential of SLMNs against $\mathrm{pH}$ condition $\left({ }^{*} p<0.01\right)$.

Since cell membranes are mainly composed of phospholipids, which contain negatively charged phosphate groups, strong positively charged SLMNs can enhance cellular affinity and the labeling efficiency by electrostatic interaction. Hence, we envisage that SLMNs are suitable labeling agents even without the use of transfection agents. The nitrogen atom of the amine group featured a lone electron pair that can bind with hydrogen protons $\left(\mathrm{H}^{+}\right)$of the water molecules to form an ammonium ion $\left(\mathrm{NH}_{3}{ }^{+}\right){ }^{31}$ In Fig. 3 (b), gel electrophoresis analysis revealed that the band of SLMNs was shifted towards the anode (downward) due to the positive surface charge of SLMNs when $100 \mathrm{~V}$ of voltage was applied to the gel matrix. Furthermore, we confirmed the variation of zeta-potentials and stability of SLMNs according to various $\mathrm{pH}$ conditions (Fig. 3 (c) and ESI†). Because the nitrogen atoms of amine groups interacted with the hydrogen protons $\left(\mathrm{H}^{+}\right)$in acidic condition, the surface of the SLMNs exhibited a positive charge below $\mathrm{pH}$ 8. In basic conditions, the nitrogen atoms were bereft of hydrogen ions $\left(\mathrm{H}^{+}\right)$ in the amine groups, and the surface charges were negative above $\mathrm{pH}$ 8. The results indicated that SLMNs exhibit positive charges under biological conditions. ${ }^{32}$

While the amount of encapsulated MNCs in SLMNs was 70 wt $\%$ through thermogravimetric analysis, SLMNs exhibited superparamagnetic behavior at $298 \mathrm{~K}$ without remanence and coercivity and the saturation of magnetization at $0.8 \mathrm{~T}$ of SLMNs was $32.28 \mathrm{emu} / \mathrm{g}_{\mathrm{MNCs}}$, which was similar to that of naked MNCs (39.76 emu/g MNCs) (Fig. 4).

To evaluate the utility of SLMNs as ultrasensitive labeling agents via MR imaging, we investigated MR images of the SLMN solutions and the signal intensities of SLMNs and then compared them with ferumoxide as a commercial MR imaging agent. The SLMN solution resulted in a stronger black color T2-weighted MR images and the corresponding relaxivity coefficient was $383.73 \mu \mathrm{M}^{-1} \mathrm{~s}^{-1}$ indicating that SLMNs were
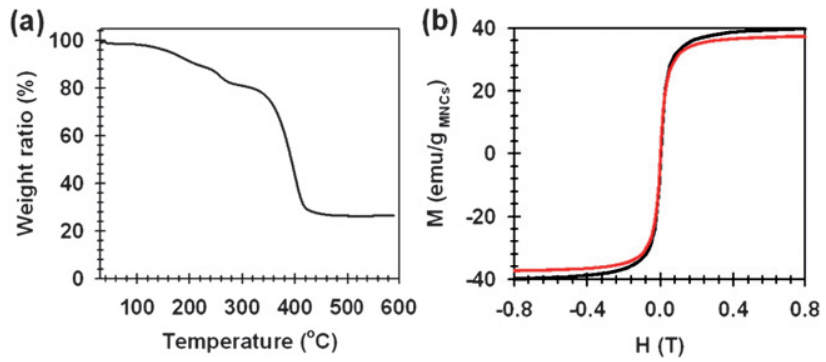

Fig. 4 (a) Thermogravimetric analysis of self-labeled magneto nanoprobes (SLMNs) and (b) magnetic hysteresis loops of MNCs (black solid line) and SLMNs (red solid line).
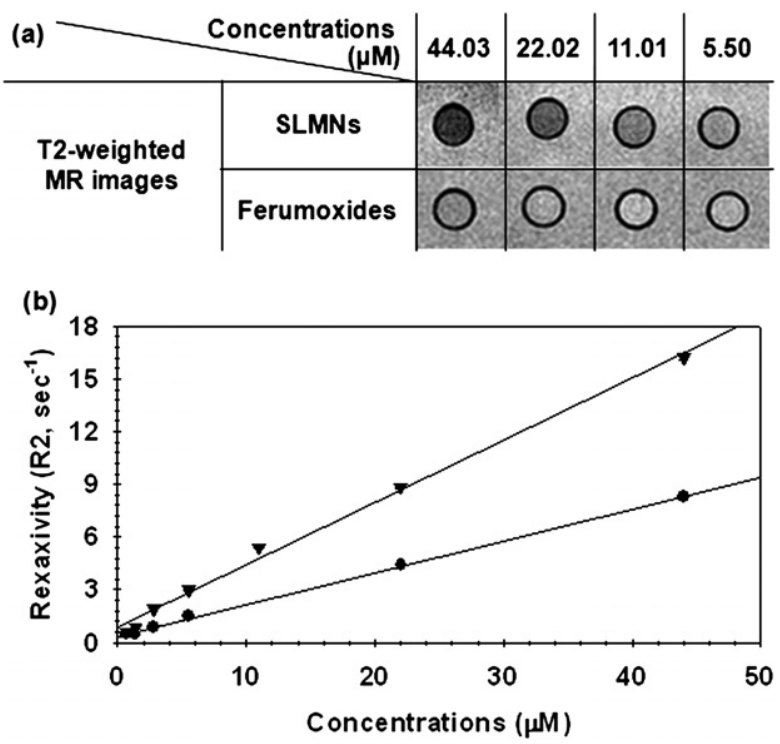

Fig. 5 (a) T2-weighted MR images and (b) relaxivity (R2) graph versus various concentrations of self-labeled magneto nanoprobes (SLMNs) $(\boldsymbol{\nabla})$ compared to ferumoxides $(\boldsymbol{\bullet})$.

sufficiently sensitive labeling agents as compared with ferumoxide (190.47 $\mu \mathrm{M}^{-1} \mathrm{~s}^{-1}$ ) (Fig. 5).

As shown in Fig. 6 (a), in vitro cytotoxic activity measured by MTT assay showed that the cell viability of SLMNs retained over $80 \%$ of the concentration of $100 \mu \mathrm{g} \mathrm{Fe}+\mathrm{Mn} / \mathrm{mL}$. In addition, we performed the biocompatibility test of SLMNs against hMSCs through the annexin V-FIT C/propidium iodide (PI) double stain method to investigate whether SLMNs may induce apoptosis. In apoptotic cells, phosphatidylserine (PS) was exposed to the outer cell membrane and annexin $\mathrm{V}$ had a high affinity to PS as a phospholipid binding protein, since the integrity of the cell membrane was breaking. PI was also used for distinction of dead or damaged cells, because PI penetrates into the membrane of dead or damaged cells. In Fig. 6 (b), SLMN $(80 \mu \mathrm{g} \mathrm{Fe}+\mathrm{Mn} / \mathrm{mL})$-treated hMSCs were detected in the lower left quadrant $(99.51 \%)$ and did not stain with either annexin V-FITC and PI, which is comparable to results with non-treated control cells $(97.21 \%)$. Also, the rate of apoptotic and necrotic cells did not differ between SLMN- treated and non-treated cells. The results demonstrate that SLMNs do not induce apoptosis and necrosis in hMSCs. 

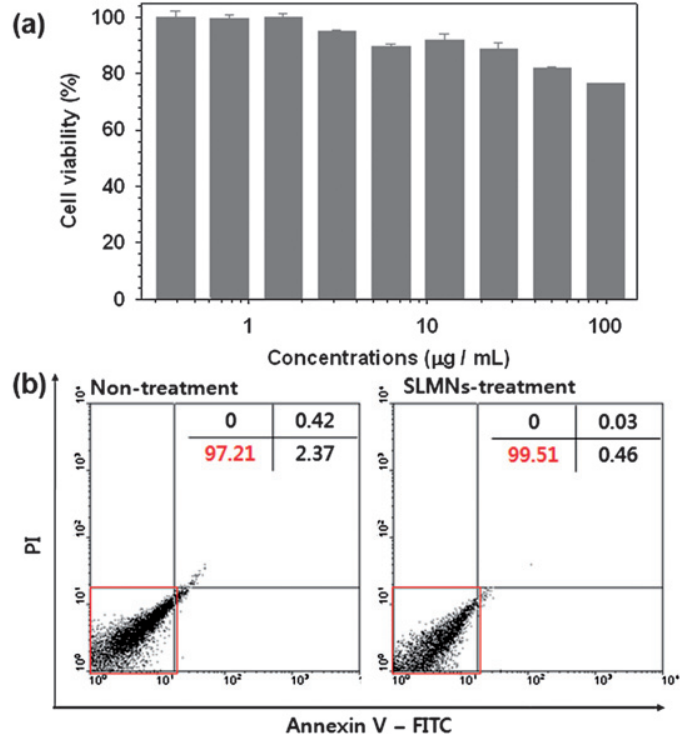

Fig. 6 (a) Cell viability of human mesenchymal stem cells (hMSCs) treated with various concentrations of self-labeled magneto nanoprobes (SLMNs) and (b) biocompatibility test of hMSCs treated with SLMNs using apoptosis detection assay (annexin V-FITC/PI double stain method); the numbers in all of the FACS data represent the percentages of each cell death mechanism: the percentages (\%) of cells suffering necrotic death (annexin $\mathrm{V}^{-} / \mathrm{PI}^{+}$; upper left), apoptotic cells (annexin $\mathrm{V}^{+} / \mathrm{PI}^{-}$; lower right), late apoptotic or secondary necrotic death (annexin $\mathrm{V}^{+} / \mathrm{PI}^{+}$; upper right) and live cells (annexin $\mathrm{V}^{-} / \mathrm{PI}^{-}$; lower left).

We next evaluated the labeling efficiency of SLMNs against hMSCs through MR contrast effect at $1.5 \mathrm{~T}$. In the T2-weighted MR images, a significant MR contrast effect was observed in SLMN-treated cells (black color) compared to non-treated control cells (bright gray color) (Fig. 7 (a)). The calculated R2 relaxivity value of hMSCs treated with SLMNs exhibited consistent results showing $253.81 \mathrm{~s}^{-1}$ (1408.12\%, $\Delta \mathrm{R} 2 / \mathrm{R} 2$ non-treatment), which is much higher than that for non-treated cells $\left({ }^{*} p<0.01\right.$, Fig. 7 (a)). Furthermore, the results from Prussian blue staining and cellular TEM images showed similar results. Prussian blue and ferric ions of the MNCs rapidly exchange electrons thereby producing dark blue colors in the intra-cellular region. In Fig. 7 (b), the image of SLMN-treated hMSCs demonstrated significant MNC uptake manifested as numerous blue spots, indicating MNCs in the cytoplasm. In contrast, no dark blue spots were observed for the non-treated cells. In the cellular TEM image, the black clusters of hMSCs treated with SLMNs indicated the engulfment of SLMNs into the intra-cellular region (Fig. 7 (c)). The content of the MNCs was $0.19 \mu \mathrm{g} \mathrm{Fe}+$ Mn per $5.0 \times 10^{5}$ cells (measured by ICP-AES). Fig. 7 (d) shows the strongly gathered SLMN-treated hMSCs upon external magnetic field (Nd-B-Fe magnet, $0.3 \mathrm{~T}$ ) for $1 \mathrm{~min}$ indicating the excellent magnetic properties of SLMNs.

Through the varieties of physical, chemical and biological experiments, the synthesized SLMNs demonstrated sufficient capability as ultrasensitive self-labeling and tracking agents via MR imaging.
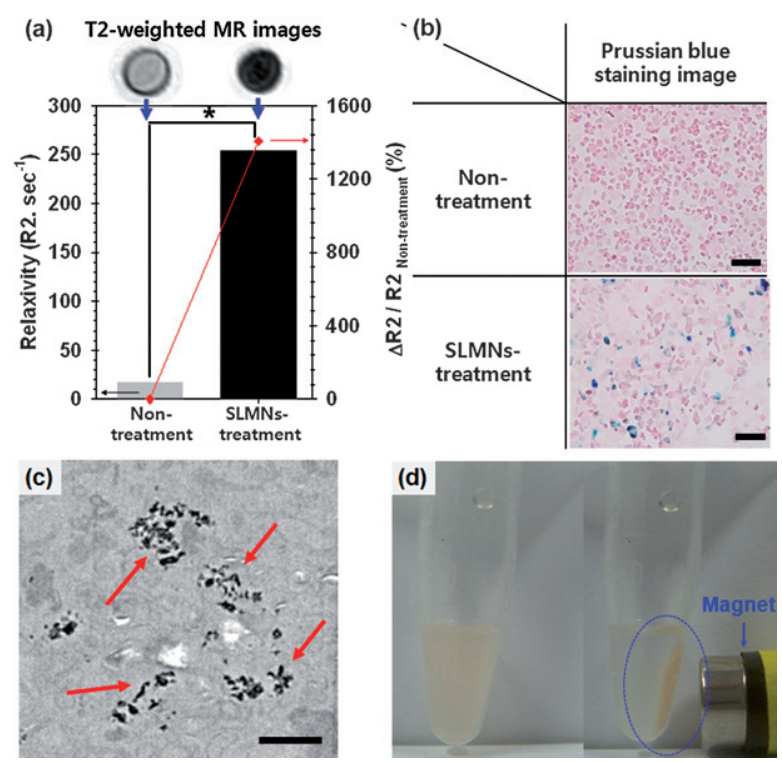

Fig. 7 (a) T2-weighted MR images and relaxivity (R2) graph (b) Prussian blue staining images, (c) TEM images of human mesenchymal stem cells (hMSCs) treated with self-labeled magneto nanoprobes (SLMNs) $(80 \mu \mathrm{g} \mathrm{Fe}+\mathrm{Mn} / \mathrm{mL})$. The red arrow of TEM images indicates the existence of SLMNs in hMSCs. And (d) dispersed in a microtube with a Nd-B-Fe magnetic field of hMSCSs treated with SLMNs for $1 \mathrm{~min}$ (scale bar: $100 \mu \mathrm{m} .{ }^{*} p<0.01$ ).

\section{Conclusions}

For cell tracking and monitoring via MR imaging, we successfully synthesized self-labeled magneto nanoprobes (SLMNs) for detection of human mesenchymal stem cells (hMSCs) without using additional transfection agents. Efficient and successful encapsulation of MNCs using tri-aminated polysorbate 80 (TP80) without loss of magnetic sensitivity produces highly water soluble nanoparticles as well as strong positively charged surface characteristics. These biologically safe and cationic SLMNs may be a potentially powerful and efficient cell tracking nanoprobe to use with MR imaging.

\section{Acknowledgements}

This study was supported by the Korea Science and Engineering Foundation (KOSEF) (No. M10641550001-08N4155-00110, M10755020001-08N5502-00110), a grant of the Korea Healthcare technology R\&D Project, Ministry for Health, Welfare \& Family Affairs, Republic of Korea. (A0851362), and grant from KRIBB Research Initiative Program.

\section{Notes and references}

1 C.-W. Lu, Y. Hung, J.-K. Hsiao, M. Yao, T.-H. Chung, Y.-S. Lin, S. H. Wu, S.-C. Hsu, H.-M. Liu, C.-Y. Mou, C.-S. Yang, D.M. Huang and Y.-C. Chen, Nano Lett., 2007, 7, 149.

2 H. Kalish, A. S. Arbab, B. R. Miller, B. K. Lewis, H. A. Zywicke, J. W. M. Bulte, L. H. Bryant Jr. and J. A. Frank, Magn. Reson. Med., 2003, 50, 275.

3 B. S. Shah, P. A. Clark, E. K. Moioli, M. A. Stroscio and J. J. Mao, Nano Lett., 2007, 7, 3071. 
4 T. D. Jeff, W. M. Bulte, B. Witwer, S.-C. Zhang, E. Strable, B. K. Lewis, H. Zywicke, B. Miller, P. Gelderen, B. M. Moskowitz, I. D. Duncan and J. A. Frank, Nat. Biotechnol., 2001, 19, 1141.

5 K. S. Cahill, G. Gaidosh, J. Huard, X. Silver, B. J. Byrne and G. A. Walter, Transplantation, 2004, 78, 1626.

6 L. Wang, J. Deng, J. Wang, B. Xiang, T. Yang, M. Gruwel, T. Kashour, B. Tomanek, R. Summer, D. Freed, D. S. Jassal, G. Dai, M. Glogowski, R. Deslauriers, R. C. Arora and G. Tian, Magn. Reson. Imaging, 2009, 27, 108.

7 H. E. Rice, E. W. Hsu, H. Sheng, D. A. Evenson, A. J. Freemerman, K. M. Safford, J. M. Provenzale, D. S. Warner and G. A. Johnson, AJR, Am. J. Roentgenol., 2007, 188, 1101.

8 J. A. Frank, B. R. Miller, A. S. Arbab, H. A. Zywicke, E. K. Jordan, B. K. Lewis, L. H. Bryant, Jr. and J. W. M. Bulte, Radiology, 2003, 228, 480.

9 B.-H. Park, J.-C. Jung, G.-H. Lee, T.-J. Kim, Y.-J. Lee, J.-Y. Kim, Y. W. Kim, J.-H. Jeong and Y. Chang, Colloids and Surfaces A: Physicochemical and Engineering Aspects, 2008, 145, 313-314.

10 A. S. Arbab, G. T. Yocum, L. B. Wilson, A. Parwana, E. K. Jordan, H. Kalish and J. A. Frank, Mol. Imaging, 2004, 3, 24.

11 D. L. Kraitchman and J. W. M. Bulte, Basic Res. Cardiol., 2008, 103, 105

$12 \mathrm{~S}$. Ju, G. Teng, Y. Zhang, M. Ma, F. Chen and Y. Ni, Magn. Reson. Imaging, 2006, 24, 611.

13 H.-T. Song, J.-s. Choi, Y.-M. Huh, S. Kim, Y.-w. Jun, J.-S. Suh and J. Cheon, J. Am. Chem. Soc., 2005, 127, 9992.

14 J. Y. S.-B. Seo, E.-S. Lee, Y. Jung, K. Kim, S.-Y. Lee, D. Kim, J.-S. Suh, Y.-M. Huh and S. Haam, J. Mater. Chem., 2008, 18, 4402.

15 X. S. K. S. Cahill, G. Gaidosh, B. J. Byrne and G. A. Walter, Proc Intl. Soc. Mag. Reson. Med., 2003, 11, 368.

16 A. S. Arbab, G. T. Yocum, H. Kalish, E. K. Jordan, S. A. Anderson, A. Y. Khakoo, E. J. Read and J. A. Frank, Blood, 2004, 104, 1217.

17 E. Pawelczyk, A. S. Arbab, S. Pandit, E. Hu and J. A. Frank, NMR Biomed., 2006, 19, 581.
18 A. S. Arbab, G. T. Yocum, A. M. Rad, A. Y. Khakoo, V. Fellowes, E. J. Read and J. A. Frank, NMR Biomed., 2005, 18, 553.

19 S. A. Anderson, J. Glod, A. S. Arbab, M. Noel, P. Ashari, H. A. Fine and J. A. Frank, Blood, 2005, 105, 420.

20 J. Yang, E.-K. Lim, E.-S. Lee, J.-S. Suh, S. Haam and Y.-M. Huh, J. Biotechnol., 2008, 136, S194.

21 H. Sadek, S. Latif, R. Collins, M. G. Garry and D. J. Garry, Regener. Med., 2008, 3, 807.

22 A. S. Arbab, L. A. Bashaw, B. R. Miller, E. K. Jordan, B. K. Lewis, H. Kalish and J. A. Frank, Radiology, 2003, 229, 838.

23 M. Babic, D. Horak, P. Jendelova, K. i. Glogarova, V. t. Herynek, M. Trchova, K. n. Likavcanova, P. Lesny, E. Pollert, M. Hájek and E. Sykova, Bioconjugate Chem., 2009, 20, 283.

24 Y. M. Huh, Y. w. Jun, H. T. Song, S. Kim, J. s. Choi, J. H. Lee, S. Yoon, K. S. Kim, J. S. Shin, J. S. Suh and J. Cheon, J. Am. Chem. Soc., 2005, 127, 12387.

25 S. Sun, H. Zeng, D. B. Robinson, S. Raoux, P. M. Rice, S. X. Wang and G. Li, J. Am. Chem. Soc., 2004, 126, 273.

26 C. Yang, X. Wang, H. Li, S. H. Goh and J. Li, Biomacromolecules, $2007,8,3365$.

27 G. S. Bethell, J. S. Ayers, W. S. Hancock and M. T. W. Hearn, The journal of biological chemistry, 1979, 254, 2572.

28 J. Yang, S. B. Park, H.-G. Yoon, Y. M. Huh and S. Haam, Int. J. Pharm., 2006, 324, 185.

29 S.-K. Yang, S. Attipoe, A. P. Klausner, R. Tian, D. Pan, T. A. Rich, T. T. Turner, W. D. Steers and J. J. Lysiak, J. Urol., 2006, 176, 830.

30 Y.-H. Chen, H.-Y. Chen, C.-L. Hsu and G.-C. Yen, J. Agric. Food Chem., 2007, 55, 1743.

31 D.-B. Shieh, F.-Y. Cheng, C.-H. Su, C.-S. Yeh, M.-T. Wu, Y.-N. Wu, C.-Y. Tsai, C.-L. Wu, D.-H. Chen and C.-H. Chou, Biomaterials, 2005, 26, 7183.

32 N. C. B. M. Vamvakaki, S. P. Armes, J. F. Watts and S. J. Greaves, J. Mater. Chem., 2001, 11, 2437. 